\title{
Article
}

\section{Making a difference for children and families: an appreciative inquiry of health visitor values and why they start and stay in post}

Whittaker, Karen, Malone, Mary, Cowley, Sarah, Grigulis, Astrida, Nicholson, Caroline and Maben, Jill

Available at http://clok.uclan.ac.uk/12603/

Whittaker, Karen ORCID: 0000-0002-3493-9396, Malone, Mary, Cowley, Sarah, Grigulis, Astrida, Nicholson, Caroline and Maben, Jill (2015) Making a difference for children and families: an appreciative inquiry of health visitor values and why they start and stay in post. Health and Social Care in the Community, 25 (2). ISSN 0966-0410

It is advisable to refer to the publisher's version if you intend to cite from the work. http://dx.doi.org/10.1111/hsc.12307/

For more information about UCLan's research in this area go to http://www.uclan.ac.uk/researchgroups/ and search for < name of research Group>.

For information about Research generally at UCLan please go to http://www.uclan.ac.uk/research/

All outputs in CLoK are protected by Intellectual Property Rights law, including Copyright law. Copyright, IPR and Moral Rights for the works on this site are retained by the individual authors and/or other copyright owners. Terms and conditions for use of this material are defined in the policies page. 
Title

Making a difference for children and families. An appreciative inquiry of health visitor aspirations, values and beliefs and why they start and stay in post.

Authors:

Karen A Whittaker ${ }^{1}$, PhD, RHV, RN

Mary Malone ${ }^{2}, \mathrm{PhD}, \mathrm{RHV}, \mathrm{RN}$

Sarah Cowley ${ }^{2}$ PhD, RHV, RN

Astrida Grigulis², PhD

Caroline Nicholson², PhD, RHV, RN

Jill Maben ${ }^{2}, \mathrm{PhD}, \mathrm{RN}$

${ }^{1}$ School of Community Health and Midwifery, College of Health and Wellbeing, University of Central Lancashire, Preston, Lancashire, United Kingdom. Kwhittaker1@uclan.ac.uk Tel: 01772893786

${ }^{2}$ Florence Nightingale Faculty of Nursing and Midwifery, King's College London, United Kingdom

This is the author accepted manuscript of the following article:

Whittaker, K.A., Malone, M., Cowley, S., Grigulis, A., Nicholson, C., Maben, J. (2015) Making a difference for children and families. An appreciative inquiry of health visitor values and why they start and stay in post. Health and Social Care in the Community. doi: 10.1111/hsc.12307, which has been published in final form at http://onlinelibrary.wiley.com/doi/10.1111/hsc.12307/abstract doi: $10.1111 / \mathrm{hsc} .12307$. This article may be used for non-commercial purposes in accordance with Wiley Terms and Conditions for Self-Archiving. 


\section{Abstract (297 words)}

The study aimed to develop an understanding of health visitor recruitment and retention by examining what existing staff and new recruits wanted from their job, their professional aspirations and what would encourage them to start and stay in employment. Following a period of steady decline in numbers the health visitor workforce in England has recently been invested in and expanded to deliver universal child public health. To capitalise on this large investment, managers need an understanding of factors influencing workforce retention and continuing recruitment of health visitors. The study was designed using an interpretive approach and involved students ( $n=17)$ and qualified health visitors ( $n=22$ ) from the north and south of England. Appreciative inquiry (Al) exercises were used as methods of data collection during 2012. During Al exercises students and health visitors wrote about: a practice experience you have felt excited and motivated by and briefly describe the factors that contributed to this. Participants were invited to discuss their written accounts of practice with a peer during an audio recorded sharing session. Participants gave consent for written accounts and transcribed recordings to be used as study data, which was examined using framework analysis. In exploring personal meanings of health visiting, participants spoke about the common aspiration to make a difference to children and families. To achieve this they expected their job to allow them to: connect with families; work with others; use their knowledge, skills and experience; use professional autonomy. The study offers new insights into health visitors' aspirations, showing consistency with conceptual explanations of optimal professional practice. Psychological contract theory illustrates connections between professional aspirations and work commitment. Managers can use these findings as part of workforce recruitment and retention strategies and for building on the health visitor commitment to making a difference to children and families.

Keywords: recruitment and retention; psychological contract; health visiting; employment; professional values 


\section{What is known about this topic}

- The newly expanded health visitor workforce in England needs retaining for delivery of universal children's services

- Escalating workloads and low job satisfaction threatens the retention of health and social care workforces.

- Psychological engagement with a job can positively impact on commitment to stay in a position

\section{What this paper adds}

- Health visitors are motivated by the aspiration to make a difference to children and families.

- Whilst in employment health visitors hold expectations that they will be able to work in ways consistent with their professional values.

- Psychological contract theory explains the importance of health visitor professional values and this knowledge has implications for what employers need to understand to address workforce recruitment and retention.

\section{Acknowledgements}

The authors are grateful to the students and qualified health visitors giving their time to participate in the study and to Dr Sara Donetto for reviewing earlier drafts of the manuscript.

\section{PRP disclaimer}

This is an independent paper based on research commissioned and funded by the Policy Research Programme in the Department of Health. The views expressed are not necessarily those of the Department.

\section{Author contributions:}

Study design: KW, AG, SC \& JM; Data collection: KW, MM, AG \& CN; Data analysis: KW, AG, JM; Manuscript preparation: KW, MM, SC, AG, CN \& JM

\section{Conflict of interest}


None

Manuscript (5,011 words)

\section{Introduction}

Issues of staff recruitment and retention are of great importance to health and social service managers because of mounting evidence that staff shortages and high turnover compromise care quality (The Lord Laming 2009, Needleman et al. 2011, Ball et al. 2014). In Britain, as elsewhere, nurses and social care staff are needed across the life course (Centre for Workforce Intelligence [CfWI], 2011, 2013), to deliver preventive interventions that can address escalating health inequalities (Marmot et al. 2010). The focus of this paper is on British health visitors, a workforce that has recently undergone large-scale transformation to grow its size and develop capabilities in leading universal child public health services (Department of Health (DH) 2013). Specifically, this paper presents findings from a health visitor recruitment and retention study incorporating appreciative inquiry (Al) approaches (Cooperrider \& Whitney 1999). A synthesis of the Al qualitative data is drawn together and informed by Cowley et al's (2014) 'orientation to practice'. Conclusions about the importance of understanding employee professional aspirations, values and attitudes to their work when managing threats to workforce recruitment and retention are based on psychological contract theory (Rousseau 2001).

\section{The health visitor workforce context}

In many Organisation for Economic Co-operation and Development (OECD) countries an ageing healthcare workforce is a particular concern (Ono et al. 2013). Replacing retired health visitors has been especially difficult as education and training places have not matched the numbers leaving (CfWI 2012). Repeated NHS workforce surveys between 2009-2012 reported that out of all nursing 
groups health visitors had: the least job satisfaction; a belief that they were under too much pressure at work; and a greater intention to leave their job (Picker Institute Europe (PIE) 2014). This was concerning given evidence that staff well-being at work is an important antecedent of staff performance and patient care experiences (Maben et al. 2012).

Between 2000 and 2010, the number of health visitors in post fell by an average of $2 \%$ annually (Health and Social Care Information Centre (HSCIC ) 2011). The policy response to reverse this decade long reduction of almost 20\% was the Health Visitor Implementation Plan 2011-2015 (DH 2011), updated as The Plan (DH 2013). The Plan supported an unprecedented focus on health visitor training and recruitment, to increase workforce numbers by almost $50 \%$ in 3 years, as well as action to revitalise professional practice commensurate with $21^{\text {st }}$ century health care needs. Since The Plan, NHS survey data reports health visitor motivation at work is improving (PIE 2015). However perceptions that service demands have also escalated, means some do not recognise positive changes in their workloads following the increase in staff numbers (Institute of Health Visiting (iHV) 2014). International studies examining staff shortages in health care indicate that the problem is multi-faceted reflecting both demand and supply factors (Ono et al. 2013). As such, Buchan \& Aiken (2008) have previously argued for solutions that include a 'focus on the motivation of nurses and incentives to recruit and retain them' (p3265) and so go beyond solely training additional numbers.

\section{Recruitment and retention evidence}

Currently those managing and developing recruitment and retention strategies for health visitors have limited work-force specific research to inform decisions. The few studies involving health visitors tend to focus on wider nursing workforce issues, e.g. the influence of gender (Muldoon \& Reilly 2003), older age on career aspirations and employment decisions (Andrews et al. 2005) and student nurse placements influence on early career job satisfaction (Murrells et al. 2009). Even in community specific studies (Leese et al. 2009, Curtis \& Glacken 2014), evidence pertaining to health 
visiting is embedded in a wider context. Thus it can be difficult to tease out specific issues for health visitors.

Nursing research, however, does reveal 'psychological dimensions' as important to retention demonstrating that intentions to stay in post are improved by psychological engagement with the job (Carter \& Tourangeau 2012) and positive workplace relationships (Tourangeau et al. 2010, Hayes et al. 2010). Other evidence shows that psychologically engaged staff are more compassionate and perform better (King's Fund 2015) and, when able to work in ways consistent with personal values, they can flourish (Wendt et al. 2011). Cowley et al (2014), in their narrative review of the literature, identified psychological dimensions of the health visiting role, expressed as values and attitudes described as part of a conceptual 'orientation to practice' comprising the values of health creation, person-centeredness and human ecology. However, these values have not been assessed as sources of influence on workforce recruitment or retention. Further, existing literature on nursing recruitment and retention offers only a limited insight into issues for health visiting. This prompted the Department of Health (England) to commission the research reported here, which aimed to develop an understanding of recruitment and retention specific to the health visitor workforce. This paper reports evidence for the objective to:

- Examine what people want from their job as a health visitor and how it links with their (professional) aspirations.

The analysis showed health visitor professional values and aspirations. In this paper we describe the importance of meeting these as part of managing workforce recruitment and retention.

\section{Methods}

An interpretive approach (Mason 2002) was used to guide the overall design of the study and choice of data collection methods used with health visitor students $(n=17)$ and practitioners $(n=22)$ as 
detailed in figure 1. Data collection methods included Al exercises from which participants for a

group interview and then individual interviews were identified. In this paper we specifically draw on the Al data (in bold, figure 1).

Scoping of arrangements for recruiting health visitor students across England.

Exercise used to select two research sites from different regions, with a Higher Education Institution (HEI) and NHS trust partnership in place. Purposive selection was used to identify one site using a centralised (regional) system of student recruitment and another using local systems/agreements for student recruitment.

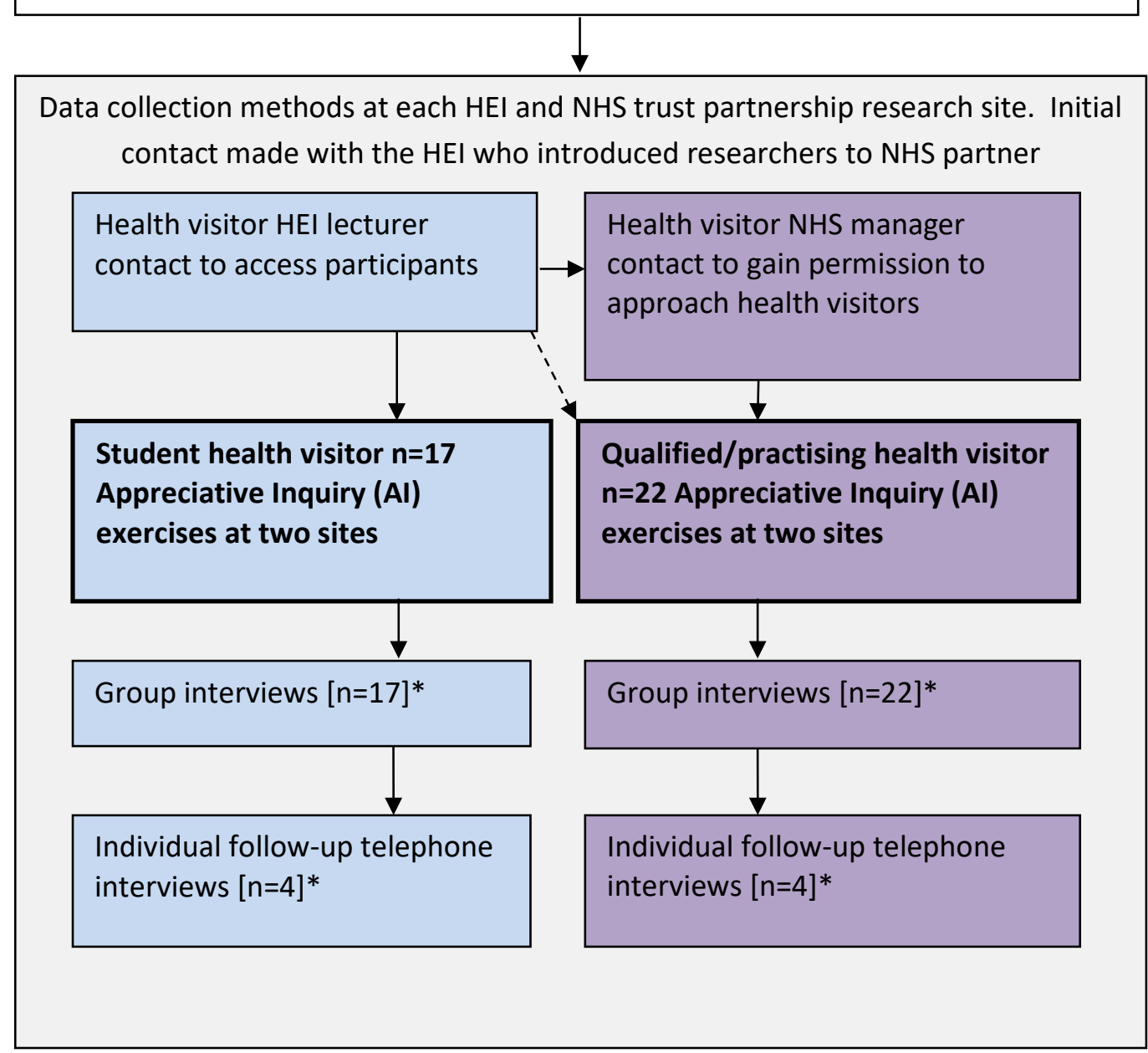

Figure 1. Overview of study design and methods of data collection (* participants from the Al exercises involved in further data collecting)

Al intentionally starts with collecting personal experiences to forward understanding and thus enables seeing new perspectives and possibilities within a situation (Nicholson \& Barnes 2013). 
When used in research, attention is directed at seeking out good practice, rather than following questions arising from a research problem (Carter et al. 2007). Within the context of this study the 'research problem' concerned staff shortages, which were believed to negatively impact on workload and morale. This created a risk that research interviews would be dominated by 'deficitfocused' accounts of practice, offering little insight into potential solutions. The Al exercises were therefore embedded within the design to counteract this risk and open the opportunity to uncover what health visitors valued about their professional role and what encouraged them to stay. A full proposal outlining all study methods and stages was reviewed by the ethics committee of King's College London, who granted permission for the study to proceed (PNM/11/12-55).

Site selection and study recruitment

Two research sites were purposively selected following a scoping exercise of arrangements for student health visitor recruitment across England (see figure 1). Each site included a Higher Education Institution (HEI)/National Health Service (NHS) trust partnership. They were located in different geographical English regions with one NHS provider (using direct student recruitment) operating across a large conurbation and the other (using centralised recruitment methods) covering a mixed urban/rural area.

Once HEI and NHS permission was granted, lecturers and NHS locality managers cascaded information to all health visitors (students and qualified staff) employed by the NHS trust. Lecturers also shared information via relevant networks and hosted 'question and answer' sessions where researchers provided verbal and written study information and details about Al exercises. Attendees indicated their interest in study participation by providing an e-mail address to which an Al exercise pro-forma was mailed. None of the attendees or subsequent participants were previously known to the researchers. 


\section{Data collection}

\section{Appreciative Inquiry (Al) exercises}

Al exercise sessions, conducted in March - August 2012, comprised of 3 parts with separate groups of students $(n=8, n=9)$ and health visitors $(n=10, n=12)$ at each site. First, participants prepared short written accounts using the Al pro forma previously mailed, which asked for: a practice experience you have felt excited and motivated by and briefly describe the factors that contributed to this. Second, participants shared accounts in pairs. Third, pairs joined others forming groups of up to six. Researchers facilitated these small groups where participants discussed common themes and story differences. This layered process of gathering individual then multiple experiences was informed by Carter's (2006) guidance that research informed by Al starts with an open-ended exploration of experiences through story telling. The Al session began with attendees reading study information sheets and providing written consent to join the study. This included permission for exercises to be audio recorded, then transcribed and used alongside written accounts as study data. Al exercises were used to inform the questions used in the next data collecting stage, the group interview, completed after a refreshment break with the same groups of participants and explored the organisational context of practice.

\section{Analysis of data}

The processes of data collection and analysis ran concurrently. The audio recordings were transcribed, numbered and anonymised for analysis. The $39 \mathrm{Al}$ stories in their original written form provided another data set and were numbered for reference. Framework Analysis (Ritchie \& Spencer 1994) was used, allowing the analysis to be 'grounded,' inductive and specific to the topic of health visitor recruitment and retention. To ensure that new themes could emerge from the data, transcripts were open-coded to generate framework categories that were refined using a priori 
categories derived from the literature. Development of thematic frameworks allowed data to be indexed using Microsoft Word vs.2010 and then charts were created for each theme or groups of themes (Ritchie \& Spencer 1994, Lacey \& Luff 2009). This was an iterative process, which captured developing ideas and their interrelationships, by engaging in discussion to refine themes and linkages supported by aide memoires, such as flowcharts, tables and visual maps of themes in the data. To maintain rigour, researchers used reflexive practices to explore personal views and assumptions and potential impact on data collection and analysis.

\section{Findings}

In total 39 health visitors and students (all women, reflecting a gender imbalance characterising this profession) submitted written Al stories and joined 1 of 8 audio-recorded group discussions of these. The health visitors were in the main older than students with over half 45 years or older and most students aged less than 45 years. On average the health visitors had 11.5 years practice experience (range 1.5 - 28 years). Students had backgrounds in different fields of nursing $(n=13)$ and midwifery $(n=4)$, and over a third had recently been employed as a community staff nurse.

The Al exercises encouraged exploration of what health visiting meant to them: the purpose of their work; the values that underpinned it; and how these values were expressed in everyday work practices. Through the Al exercises participants expressed beliefs central to their professional role and that collectively represented a distinctive set of values for health visiting practice. This was summed up across the groups by the frequently-expressed aspiration to 'make a difference to children and families'. Underpinning this aspiration were four themes: (1) privilege to connect with families; (2) working with others; (3) using knowledge, skills and experience; (4) professional autonomy to respond appropriately and flexibly to needs. These are explored below with participant quotes (HV=health visitor; St=student) illustrating our analysis. The themes represent what health visitors value about their practice, which therefore need acknowledging when addressing workforce retention issues, as one student explains: 'I just want work to value what I value'. (St13) 


\section{Privilege to connect with families}

A common thread through the Al stories shared by students and health visitors concerned the connections they developed with individual families and the wider community. Some experienced it as a privilege of the role as it afforded opportunity to witness the lives of others, often at critical moments and over a period of time. The following health visitor excerpt draws attention to the sense of enthusiasm generated by client contacts:

Throughout the 26 years of my health visiting career I have valued the unique and privileged opportunity to work with families with young children over a period of time. No two families are the same and each and every birth notification and "movements-in" presents exciting challenge. The first time you knock on the door you are starting a new and exciting journey. (HV6)

In explaining her Al story she adds: 'I think that's one of the main reasons I like the job' (HV6)

Another commented on how such work 'made me feel energised and the reason why I carry on doing the job' (HV5).

Similarly students described coming 'away feeling very humbled' (St2) following home visits 'that had highlighted people's strength in the face of adversity' (St2). Privilege too was mentioned when appreciating that the home visiting role provided a window into the lives of others as well as an opportunity to act:

You're in a really important position to actually see it and do something about it. It's a 'privileged' role, $[\ldots .$.$] because there's not very many people that can be in a clients' home on$ a regular basis. (St1) 
In explaining their contact with families qualified health visitors noted that a visible presence in community settings, such as clinics and groups, was important for 'being known' (HV20), and for improving accessibility if parents needed to approach someone. In some cases this involved mothers advocating for others in the community:

Many is the time it was the mothers who came from the maisonettes to tell us about a child that had moved in and how worried they were about that particular mother. (HV14)

Other examples referred to individuals accessing help for themselves using the knowledge that the health visitor would be available at a specific venue each week. One noted her recent experience where a mother had 'shut the door and said, "I haven't got a health visitor"' then the next week 'had come and sought me out at the clinic and asked for something' (HV16). Another explained how a mother had actively sought her out following a bereavement anniversary:

She didn't really want to talk about the child's sleeping problem, because she knows me, and I know her, and I was with her through that time, that awful time. .... if she didn't know who was going to be in clinic, that [opportunity for contact] would have been lost. She wouldn't have come (HV2).

\section{Working with others}

Being present in community settings was also indicated as a means to work with other professionals. In the following example where the health visitor facilitated a postnatal support group, the coordination with the midwifery-led antenatal sessions afforded a comprehensive maternal-child care service with the involvement of a range of professionals:

It was run every week and the GPs were part of it, the practice nurses would come in, the physios would come in, the counsellor would give me a bit of support afterwards. We ran it 
when the midwife had her antenatal clinic, so the mums would seep from one to the other (HV9).

In addition to making help accessible to families, health visitors identified that working cooperatively with others 'increased [their] own knowledge of resources and services in supporting children and families with complex health needs' (HV3). They were clear of the benefit in 'know[ing] who to go to for an instant answer rather than going round in circles' (HV3). In short, possessing local knowledge and using partnerships felt 'empowering' (HV3) because: 'what makes the job easier is accessing services for families' (HV13).

Similarly, students appreciated that offering assistance to families often meant working as part of a wider multi-professional team and drawing on the wider community services such as children's centres:

So that light-bulb moment for me was the fact that we're out there in the community, you're in a family, you see something that could be improved within that family, and you've got the opportunity to do it and say something to suggest them trying something different or suggest a children's centre activity or whatever it might be for that family. (St2)

In one student account of experiences of working with child protection cases, emphasis is put on early intervention and collegiate effort to make a difference:

I've seen the difference that you can make where you've got all the different agencies working and putting in time. [....] so working with the other agencies, the family went from being in chaos and fear to where the children started thriving in school and thriving at home as well. (St4)

Witnessing these experiences as part of intervention strategies for families were described as 'inspiring' (St4) and informed a professional commitment to health visiting: 
Early intervention and prevention motivates me. I wholeheartedly believe this is the way forward and health visitors are placed in a key position to achieve this (St8).

Using knowledge, skills and experience

For students, starting a health visiting career offered professional progression building on prior nursing or midwifery experiences as: 'you have to develop to become a health visitor' (St7). It enabled them to shift focus towards health promotion and early intervention, develop their knowledge and draw on communication and assessment skills informed by specific models of intervention that support person-centre practice.

I have no previous experience professionally with postnatal depression and am aware of the limitations of resources within the local area. Despite receiving training in Solihull and motivational interviewing, I was not sure how best I could support and welcomed a potential opportunity here to 'make a difference'! I listened to her [...]. She agreed to speak to her GP and made an appointment, in addition to welcoming my offer of further support. I have welcomed this opportunity to further support this Mum and others on my future caseload.

Similarly the qualified health visitors identified role satisfaction when they had been able to act using their specialist knowledge and apply skills specific to client need. In one Al story the health visitor referred to job satisfaction from working with families seeking asylum, partly because she felt appreciated, but also because she:

...had a manageable caseload and sufficient time to listen to clients and to get to know them. The team was well managed and there was good morale. I felt I was able to fully use my skills to impart health promotion to a population that might otherwise have felt totally neglected. (HV1) 
This health visitor felt she was making a difference because she could control her workload and had time to form good relationships with families. Furthermore, in this job she drew on her assets and put her professional knowledge and skills to appropriate use.

Some health visitors felt frustrated that the period of workforce reduction had limited opportunities to 'embrace the whole role' (HV8) and practice certain skills as activities were redistributed across the skill mix team. The challenge was in 'just keeping up to date with weaning and sleeping and all of those behavioural snippets' (HV12).

Becoming a practice teacher had resolved some frustrations, as the provision of student learning experiences legitimated exercising professional autonomy and involvement in a broader range of activities. Furthermore, practice teaching offered career progression and time spent developing students gave the job additional meaning:

And [as a practice teacher] you'll be able to impart all that experience and information, you're giving that over to somebody else and you can see them grow into that role. And you're growing the workforce as well, the profession is continuing. (HV15)

\section{Professional autonomy to respond appropriately and flexibly to needs}

Within written Al accounts there were numerous short statements expressing a desire to work 'autonomously'. In the verbal accounts, 'autonomy' emerged as necessary for managing work and also delivering a preferred style of practice, which drew on their specific knowledge and skills. For both students and qualified health visitors this was a desire to tailor the service to each family perspective, which may require acting on topics other than those professionally determined: 
.... motivated that (I) have made a difference by giving advice that is realistic for that family; recognising and being able to tailor/agenda match care/advice that is most relevant and pertinent to that family/child. (St14)

For me, I could be doing a developmental check, and from that check I could see vulnerability, some targeted work that needs doing, carrying it forward depending on my assessment and the needs... (HV8)

In 'carrying it forward', to gain maximum effectiveness from practice, students and health visitors assumed that freedom to use initiative or discretion was necessary. In a sense, professional autonomy was a critical aspect of practice, fuelling the interplay of the other aspects supporting a feeling 'that I was making a difference' (HV11). This point is brought together in the following example:

...because I know her and I know the history of domestic violence and the impact, I feel that I picked things up that might not have been picked up on because I did the check at home rather than in a clinic and the mum sort of opened up to me about a few things. So, if you haven't got that closeness and that continuity, things like that can slip through the net. So I'm now going to do lots of referrals from that visit and I'm going to see the mum again. Whereas that might not have happened... (HV21)

Here, the health visitor emphasises knowing the mother, understanding the history and valuing relationship continuity, which is aided by the autonomous decision to complete a home visit. Together this appeared to aid a productive contact that connected the mother with relevant services. For students these needs-focused contacts were highly reaffirming and led to comments such as: 'that's what would drive me' (St10) and convictions to 'try to continue to practice autonomously after qualification' (St14). 
The four themes identified through the analysis were mapped to core values embedded within the 'orientation to practice' identified by Cowley et al. (2014) and summarised in table 1 . Together the values identified within this empirical study and those within the orientation to practice, indicate what health visitors need to achieve a psychological connection with their roles. The purposeful endeavour of health visiting was supported by a belief in their salutogenic activities and behaviours which operationationalise human-valuing through relationship formation and acknowledgment of the individual context of each family's life. That is, they relished the opportunity to work with families to develop helping relationships, which provided the vehicle for person-centred practice.

\begin{tabular}{l|l|l|l|}
$\begin{array}{l}\text { The health visitor } \\
\text { workforce values } \\
\text { mapped against the } \\
\text { orientation to practice }\end{array}$ & $\begin{array}{l}\text { Salutogenic: } \\
\text { generate good health }\end{array}$ & $\begin{array}{l}\text { Human valuing: } \\
\text { person-centred }\end{array}$ & $\begin{array}{l}\text { Ecological: } \\
\text { accounting for the } \\
\text { person's situation }\end{array}$ \\
\hline $\begin{array}{l}\text { Sense of privilege to } \\
\text { connect with families }\end{array}$ & $\begin{array}{l}\text {-Work directly with } \\
\text { families and over a } \\
\text { period of time } \\
\text {-Take on challenge to } \\
\text { invest in health action }\end{array}$ & $\begin{array}{l}\text {-Supporting people } \\
\text { who might otherwise } \\
\text { be marginalised } \\
\text {-Time to listen and } \\
\text { develop relationships }\end{array}$ & $\begin{array}{l}\text {-Entering the client's } \\
\text { space } \\
\text {-Being visible and } \\
\text { available in the } \\
\text { community }\end{array}$ \\
\hline $\begin{array}{l}\text { Using knowledge, } \\
\text { skills and experience }\end{array}$ & $\begin{array}{l}\text {-To deliver health } \\
\text { promoting messages } \\
\text {-Share knowledge to } \\
\text { invest in workforce }\end{array}$ & $\begin{array}{l}\text {-Apply knowledge and } \\
\text { skills to make a } \\
\text { difference to children } \\
\text { and families }\end{array}$ & $\begin{array}{l}\text {-Understanding the } \\
\text { wider context and } \\
\text { factors acting as } \\
\text { resource or constraint }\end{array}$ \\
\hline Working with others & $\begin{array}{l}\text {-To seize opportunities } \\
\text { to access resource } \\
\text { - Learning from } \\
\text { connecting with others }\end{array}$ & $\begin{array}{l}\text {-Knowledge of the } \\
\text { wider workforces to } \\
\text { signpost appropriately }\end{array}$ & $\begin{array}{l}\text {-Work with others to } \\
\text { provide } \\
\text { complementary and } \\
\text { comprehensive care }\end{array}$ \\
\hline $\begin{array}{l}\text {-Use of discretion to } \\
\text { act opportunistically } \\
\text { and early enough }\end{array}$ & $\begin{array}{l}\text {-To manage own time } \\
\text { to be able tailor each } \\
\text { contact } \\
\text {-Use initiative to } \\
\text { decide on future action }\end{array}$ & $\begin{array}{l}\text {-To make referrals and } \\
\text { work with others to } \\
\text { connect family to } \\
\text { other community } \\
\text { resources }\end{array}$ \\
\hline
\end{tabular}

Table 1. The health visitor workforce values mapped against the 'orientation to practice'

They valued having enough professional autonomy to use their knowledge and experience, to tailor client focused approaches to match pressing needs and maintain respectful relationships. They spoke of being able to act on behalf of the child within the context of the family and wider 
community and thereby fulfil a desire to work alongside and learn from others to ensure provision of comprehensive care. They understood delivery of a universal service, which brought them into contact with all families having a baby, as an opportunity to use and apply health promoting knowledge, reach children or parents whose needs might otherwise be overlooked and gain privileged insights into the lives of others. Witnessing life changes and the strengths of others was inspiring, which provided motivation to do a job that allowed sufficient autonomy to practice on behalf of families to invest in good health.

Collectively the Al stories provide an indication of what is important to health visitors about their roles; summarised as four aspects of practice that lead them towards the overall goal of making a difference to children and families. Involvement in each aspect is intrinsically rewarding, providing an experience that feels worthwhile and enables a sense of job accomplishment.

\section{Discussion}

As indicated in the background to this study, there have been ambitious policy and financial investments made in health visiting in England (CfWI 2012) to address workforce recruitment and retention challenges. The future success of these investments now rest on continuing to recruit the right people and retain a workforce ready and capable of working to The Plan (DH 2013). Managers are challenged to develop and support new practice and they must do this whilst facing staff concerns that escalating service demands are cancelling-out previously made investments (iHV 2014). Importantly, where demands negatively impact on staff well-being, patient experiences become compromised (Maben et al. 2012) and lowered job satisfaction challenges workforce retention. 
Prior research suggests that attention to employee aspirations and motivations is important, given that psychological engagement with work can impact on employment decisions (Carter \& Tourangeau 2012) and professional practice (The King's Fund 2015). Within this study, the health visitors and students were able to express through writing and sharing Al stories their professional values, what inspired them and in doing so, explain what they wanted from their job and their professional aspirations. Indeed, like social workers and teachers included in research by Wendt et al. (2011), health visitors in this study, appear to thrive on meeting those values even when faced with challenging client situations. This provides an opportunity to draw on human resources literature and within it, psychological contract theory (Rousseau 2001), which explains employeeemployer relationships and factors impacting on workforce recruitment and retention. Principally the theory describes the informal obligations and expectations that employees and employers hold for each other (Coyle-Shapiro \& Parzefall 2008). Breaches or violations to this contract arise when organisations are perceived to reneged on promises or when expectations are incongruent (Morrison \& Robinson 1997), resulting in a weakened commitment by employees to stay with the employer (Sturges \& Guest 2001).

For those in professional roles, Thompson \& Bunderson (2003) contend that psychological contracts include an 'ideology-infused' dimension that accommodates the values with which members of the professional group identify. Empirical evidence from medicine (Bunderson 2001), nursing (O'Donohue \& Nelson 2007) and education (Bal \& Vink 2011) supports the influence of this dimension and demonstrates how employees expect employing organisations to provide environments that support preferred professional practice. The conceptual description of health visiting work offered by Cowley et al. (2014) and the values of health creation, person-centeredness and human ecology embedded within it, represent this 'ideology-infused' dimension of professional work and therefore indicate what are likely to be important elements of the psychological contract for employment as a health visitor. Recruitment and retention is complex with many factors at play. One important point is that managers and policy makers need knowledge of these core values and 
how to support health visitors to achieve them, if aiming to recruit and retain practitioners able to make a difference to children and families.

A limitation of the study was that participants were self-selecting and did not include those in the pre-application phase. Consequently, we are unable to say whether those not able to participate or who choose not to, would share the same values, or whether such values are typically developed as part of role socialisation. Also, whilst the aspirations and values are identified as motivators for practice, motivation-hygiene theory (Herzberg 1974) suggests this does not necessarily indicate that their absence acts as a de-motivator. A criticism of using an Al approach could be that the research was restricted to positive stories, given the focus on aspirations and strengths. However, the inclusion of facilitated discussions provided the opportunity to open up the written stories and so realities concerning staffing, commissioning and grading that were perceived to undermine these positive accounts were also shared. An example was the account that team composition and workforce shortage restricted the opportunity to practice across the breadth of the role. Thus the inclusion of written and discussed stories allowed a balanced perspective on practice to be shared and allowed participants to explore their aspirations and link these to the realities of delivering a contemporary health visiting service.

\section{Implications for Managers and Local Policy}

To meet the challenge of recruiting the right people who feel psychologically connected to the health visiting role, managers should ensure that selection methods include a review of professional values, checking for consistency with orientation to practice. In addition, to reduce mismatched expectations that could contribute to a breach of psychological contract, policies enabling practices

(such as shadowing) that facilitate informed career choices and realistic role expectations should be introduced. Opportunities should be built into recruitment processes, given evidence that early career graduates can have high expectations of their employers anticipating guidance with career 
management and training opportunities (Robinson et al. 2006; Sturges \& Guest 2001). If these expectations are not met, they become a source of dissatisfaction and are experienced as psychological contract violation, which in-turn threatens retention (Maben 2008).

Managers should develop effective communication with their staff to allow clearer expression of expectations and transparency of the psychological contract (Guest \& Conway 2002). Effective communication where values are shared is also likely to engender a trusting culture, which for health visitors would provide a helpful environment for exercising professional autonomy and actions for achieving the aspiration to make a difference to children and families. This would be part of providing suitable conditions for work that health visitors expect from their managers and that in return they will honour through providing a professional service.

\section{Conclusion}

In this paper the example of health visiting has been used to illustrate how professional aspirations link to job purpose and satisfaction. Psychological contract theory allows the meaning of professional groups' aspirations and values to be explained in terms commitment to an employment situation. The contribution to knowledge is twofold. Firstly the empirical evidence of professional aspirations that illuminate the conceptual 'orientation to practice' (Cowley et al. 2014) helps explain what motivates health visitors. Secondly the paper adds to current knowledge about what managers need to understand when addressing workforce retention; that is to recognise what employees' value in their professional role. Health visitors prize knowing families and other professionals to optimise care by improving accessibility of community resources. They also value using their knowledge to make decisions and professional autonomy to provide person-centred care. Managers supporting these values would be enabling a job situation which allows health visitors to work within their ideologically-infused framework, the health visiting 'orientation to practice' (Cowley et al. 2014), which seems likely to enhance job satisfaction, and therefore motivation to stay in post. At 
the same time this would help managers to get the most from the workforce when providing services directed at achieving child and family health outcomes.

\section{References}

Andrews J., Manthorpe J., \& Watson R. (2005) Employment transitions for older nurses: a qualitative study. Journal of Advanced Nursing 51(3), 298-306.

Bal P.M. \& Vink R. (2011) Ideological currency in psychological contracts: the role of team relationships in a reciprocity perspective. The International Journal of Human Resource Management 22(13), 2794-2817.

Ball J.E., Murrells T., Rafferty A.M., et al. (2014) 'Care left undone' during nursing shifts: associations with workload and perceived quality of care. BMJ Quality \& Safety 23, 116-125. doi:10.1136/bmjqs-2012-001767

Buchan, J. \& Aiken, L. (2008) Solving nursing shortages: a common priority. Journal of Clinical Nursing, 17 (24), 3262-3268.

Bunderson J.S. (2001) How work ideologies shape the psychological contracts of professional employees: doctors' responses to perceived breach. Journal of Organizational Behavior 22(7), 717741.

Carter B. (2006) "One expertise among many": working appreciatively to make miracles instead of finding problems. Journal of Research in Nursing 11(1), 48-63.

Carter B., Cummings J., \& Cooper L. (2007) An exploration of best practice in multi-agency working and the experiences of families of children with complex health needs. What works well and what needs to be done to improve practice for the future? Journal of Clinical Nursing 16(3), 527-539. 
Carter M.R. \& Tourangeau A.E. (2012) Staying in nursing: what factors determine whether nurses intend to remain employed? Journal of Advanced Nursing 68(7), 1589-1600.

Centre for Workforce Intelligence (CfWI) (2011) Workforce Risks and Opportunities: Adult Social Care. Mouchel Management Consulting Ltd. Woking, Surrey.

Centre for Workforce Intelligence (CfWI) (2012) Workforce Risks and Opportunities: Health Visitors. Education commissioning risks summary from 2012. Mouchel Management Consulting Ltd. Woking, Surrey.

Centre for Workforce Intelligence [CfWI] (2013) A strategic review of the future healthcare workforce. Informing the nursing workforce. Centre for Workforce Intelligence, London.

Cooperrider D.L. \& Whitney D. (1999) Appreciative Inquiry: A positive revolution in change. In The change handbook: Group methods for shaping the future (Holman P. \& Devane T., eds) pp 245-261. Berrett-Koehler Publishers, San Francisco, CA.

Coyle-Shapiro J.A.M. \& Parzefall M. (2008) Psychological Contracts. In The SAGE Handbook of organizational behavior (Cooper C.L. \& Barling J., eds) pp 17-34. Sage. London.

Cowley S., Whittaker K., Malone M., et al. (2014) Why health visiting? Examining the potential public health benefits from health visiting practice within a universal service: A narrative review of the literature. International Journal of Nursing Studies 52(1), 465-480.

Curtis EA, Glacken M. (2014) Job satisfaction among public health nurses: a national survey. Journal of Nursing Management 22(5):653-663 
Department of Health (2011) Health Visitor Implementation Plan 2011-15. Department of Health, London.

Department of Health (2013) The National Health Visitor Plan: progress to date and implementation beyond 2013. Department of Health, London.

Guest D.E., \& Conway N. (2002) Communicating the psychological contract: an employer perspective. Human Resource Management Journal 12(2): 22-38.

Hayes B., Bonner A., \& Pryor J. (2010) Factors contributing to nurse job satisfaction in the acute hospital setting: a review of recent literature. Journal of Nursing Management 18(7), 804-814.

Health and Social Care Information Centre (HSCIC) (2011) NHS Workforce: Summary of staff in the NHS: Results from September 2010 Census . 2011. The Health and Social Care Information Centre, Workforce and Facilities Team. Available at: http://www.hscic.gov.uk/catalogue/PUB02070 (Accessed on 28/4/15)

Herzberg, F. (1974). Motivation-hygiene profiles. Organizational Dynamics, 3(2), 18-29.

Institute of Health Visiting (iHV) (2014) Institute of Health Visiting: Excellence in Practice. Year Two Report. 2013/2014. Available at: http://www.ihv.org.uk/news events/annual reports (Accessed on 07/04/15)

Lacey A. \& Luff D. (2009) Qualitative Research Analysis The NIHR RDS for the East Midlands / Yorkshire \& the Humber. 
Leese B., Storey C., \& Cheater F. (2009) Retaining primary and community nurses over the age of 50 years: the views of managers. Journal of Nursing Management 17(8), 975-985.

Maben J. (2008) Employee engagement and retention in the nursing workforce: A case study of an inner-London acute trust. King's College and London School of Hygiene and Tropical Medicine, London.

Maben J., Peccei R., Robert G., et al. (2012) Patients' experiences of care and the influence of staff motivation, affect and wellbeing. Final report. UK National Institute for Health Research Service Delivery and Organisation Programme. Available at:

http://www.nets.nihr.ac.uk/ data/assets/pdf file/0007/85093/ES-08-1819-213.pdf (Accessed on $23 / 2 / 15)$

Marmot, M., Allen, J., Goldblatt, P., et al.(2010) Fair Society, Healthy Lives: Strategic Review of Health Inequalities in England Post-2010. The Marmot Review, London. Available from: http://www.instituteofhealthequity.org/projects/fair-societyhealthylives-the-marmot-review (Accessed on 04/05/14).

Mason J. (2002) Qualitative Researching, 2nd Ed edn. Sage, London.

Morrison, E. W. \& Robinson, S. L. (1997) When employees feel betrayed: A model of how psychological contract violation develops. Academy of Management Review, 22(1), 226-256.

Muldoon O.T. \& Reilly J. (2003) Career choice in nursing students: gendered constructs as psychological barriers. Journal of Advanced Nursing 43(1), 93-100. 
Murrells T., Robinson S., \& Griffiths P. (2009) Nurses' job satisfaction in their early career: is it the same for all branches of nursing? Journal of Nursing Management 17(1), 120-134.

Needleman, J., Buerhaus, P., Pankratz, V. S., Leibson, C. L., Stevens, S. R., and Harris, M. (2011). Nurse Staffing and Inpatient Hospital Mortality. New England Journal of Medicine 364(11), 1037-1045.

Nicholson, C., \& Barnes, J. (2013) Appreciative Inquiry in Participatory research in Palliative care. (Hockley, J., Heimerl, K. and Froggatt, K. eds) Oxford University Press, Oxford.

O'Donohue W. \& Nelson L. (2007) Let's be professional about this: ideology and the psychological contracts of registered nurses. Journal of Nursing Management 15(5), 547-555.

Ono T., Lafortune G., \& Schoenstein M. (2013) Health Workforce Planning in OECD Countries: A Review of 26 Projection Models from 18 Countries. OECD Health Working Papers, No. 62. 2013. OECD Publishing. Available at: http://dx.doi.org/10.1787/5k44t787zcwb-en (Accessed on 28/4/15)

Picker Institute Europe. (2014) Historical Staff Survey Results. http://www.nhsstaffsurveys.com/Page/1021/Past-Results/Historical-Staff-Survey-Results/ (Accessed on $28 / 4 / 15)$

Picker Institute Europe (2015) National NHS Staff Survey 2014. http://www.nhsstaffsurveys.com/Page/1021/Past-Results/Historical-Staff-Survey-Results/ (Accessed on $28 / 4 / 15)$ 
Ritchie J. \& Spencer L. (1994) Qualitative data analysis for applied policy research. In Analysing Qualitative Data (Bryman A. \& Burgess R.G., eds) pp 173-194. Routledge, London.

Robinson, S., Murrells, T., \& Clinton, M. (2006) Highly qualified and highly ambitious: implications for workforce retention of realising the career expectations of graduate nurses in England. Human Resource Management Journal 16(3), 287-312.

Rousseau, D. M. (2001). Schema, promise and mutuality: The building blocks of the psychological contract. Journal of Occupational and Organizational Psychology 74(4), 511-541. DOI: $10.1348 / 096317901167505$

Sturges J. \& Guest D. (2001) Don't leave me this way! A qualitative study of influences on the organisational commitment and turnover intentions of graduates early in their career. British Journal of Guidance and Counselling 29(4), 447-462.

The King's Fund (2015) Staff engagement. Six building blocks for harnessing the creativity and enthusiasm of NHS staff. The King's Fund, London. Available at: http://www.kingsfund.org.uk/publications/staff-engagement (Accessed on 28/4/15)

Thompson J.A. \& Bunderson J.S. (2003) Violations of principle: ideological currency in the psychological contract. Academy of Management Review 28(4), 571-586.

Tourangeau A.E., Cummings G., Cranley L.A., et al. (2010) Determinants of hospital nurse intention to remain employed: broadening our understanding. Journal of Advanced Nursing 66(1), 22-32.

Wendt S., Tuckey M.R., \& Prosser B. (2011) Thriving, not just surviving, in emotionally demanding fields of practice. Health \& Social Care in the Community 19(3), 317-325. 
